\title{
Sanctions, Partner Recognition, and Variation in Mutualism
}

\author{
Jeremy B. Yoder ${ }^{1, \star}$ and Peter Tiffin ${ }^{2}$ \\ 1. Department of Forest and Conservation Sciences, University of British Columbia, Vancouver, British Columbia V6T 1Z4, Canada; \\ 2. Department of Plant Biology, University of Minnesota, Saint Paul, Minnesota 55108 \\ Submitted August 19, 2016; Accepted May 10, 2017; Electronically published August 23, 2017 \\ Dryad data: http://dx.doi.org/10.5061/dryad.p2s02.
}

\begin{abstract}
AвSTRACT: Mutualistic interactions can be stabilized against invasion by noncooperative individuals by putting such "cheaters" at a selective disadvantage. Selection against cheaters should eliminate genetic variation in partner quality - yet such variation is often found in natural populations. One explanation for this paradox is that mutualism outcomes are determined not only by responses to partner performance but also by partner signals. Here, we build a model of coevolution in a symbiotic mutualism, in which hosts' ability to sanction noncooperative symbionts and recognition of symbiont signals are determined by separate loci, as are symbionts' cooperation and expression of signals. In the model, variation persists without destabilizing the interaction, in part because coevolution of symbiont signals and host recognition is altered by the coevolution of sanctions and cooperation, and vice versa. Individual-based simulations incorporating population structure strongly corroborate these results. The dual systems of sanctions and partner recognition converge toward conditions similar to some economic models of mutualistic symbiosis, in which hosts offering the right incentives to potential symbionts can initiate symbiosis without screening for partner quality. These results predict that mutualists can maintain variation in recognition of partner signals or in the ability to sanction noncooperators without destabilizing mutualism, and they reinforce the notion that studies of mutualism should consider communication between partners as well as the exchange of benefits.
\end{abstract}

Keywords: symbiosis, mutualism, coevolution, population genetics.

\section{Introduction}

Mutually beneficial interactions between species pose two related conundrums. First, how are mutualisms maintained in the face of the apparent advantages to individuals who accept resources or services but provide none in return? And second, given a mechanism that prevents the evolution of noncooperative participants, why do members of interacting species vary in mutualistic quality?

The first conundrum may be solved through selective dynamics that offset cheaters' advantage. Mutualists might avoid or discontinue interaction with cheaters (Trivers 1971; Axel-

\footnotetext{
* Corresponding author. Present address: Department of Biology, Californi State University, Northridge, California 93130; e-mail: jbyoder@gmail.com. ORCIDs: Yoder, http://orcid.org/0000-0002-5630-0921.
}

Am. Nat. 2017. Vol. 190, pp. 491-505. (C) 2017 by The University of Chicago. 0003-0147/2017/19004-57193\$15.00. All rights reserved. DOI: $10.1086 / 693472$ rod and Hamilton 1981; Foster et al. 2006) or might reduce or cut off rewards provided to them (Bull and Rice 1991; West et al. 2002a, 2002b; Sachs et al. 2004; Akçay and Simms 2011). Some authors have differentiated the former approach as "partner choice," though both are in some sense "sanctions" that actively deny the full benefit of mutualism to cheaters and avoid the full cost of interacting with them. By contrast, in "partner-fidelity feedback," cooperative partners receive greater rewards without any active "decision" by the rewardproviding species, simply because healthy individuals produce more rewards (Doebeli and Knowlton 1998; Weyl et al. 2010; Frederickson 2013) or because rewards are accessible only to cooperative partners (Archetti et al. 2011a, 2011b). Each of these mechanisms ensures that noncooperators are at a long-term fitness disadvantage even if they have an advantage over cooperators in the short term.

Such anticheating mechanisms have been found in many mutualisms. Legumes can cut off resources to root nodules in which rhizobial bacteria do not fix nitrogen (Kiers et al. 2003; Batstone et al. 2017) and can scale these sanctions quantitatively to reduce support for less productive nodules (Kiers et al. 2006). In the obligate brood pollination mutualisms of yuccas and figs, in which pollinators lay eggs in flowers in the course of delivering pollen, host plants abort flowers that are too badly damaged by pollinator oviposition or that receive poor-quality pollination (Pellmyr and Huth 1994; Jandér and Herre 2010). Ant-protected shrubs reduce the growth of domatia, structures that house protective ants, on branches that suffer herbivore damage, and this may be a sanctioning response to poor protection by the ants (Edwards et al. 2006b) or an example of partner-fidelity feedback (Weyl et al. 2010).

These solutions to the first conundrum of mutualism create the second conundrum. Partner choice, sanctions, and partner-fidelity feedback should all lead to fixation of cooperative genotypes (Axelrod and Hamilton 1981; Doebeli and Knowlton 1998; West et al. 2002a, 2002b). Similarly, if interacting mutualists maximize their own fitness by matching each other, coevolution should reduce diversity in both interacting species (Kiester et al. 1984; Kopp and Gavrilets 2006; Yoder and Nuismer 2010). Nevertheless, genetic vari- 
ation in partner quality is widely observed in natural populations of mutualists (Heath and Stinchcombe 2014; Jones et al. 2015), including in many interactions where mutualismstabilizing mechanisms have been studied directly, such as rhizobial bacteria and their legume hosts (Simms and Taylor 2002; Heath and Tiffin 2009), mycorrhizal fungi (Hoeksema 2010), ant bodyguards (Ness et al. 2006), and brood pollinators (Pellmyr and Huth 1994; Herre and West 1997; Holland and Fleming 1999).

Coevolutionary dynamics that can maintain genetic variation in interacting species are known - not from mutualism, but from antagonistic interactions. Host-parasite interactions or competition can either create frequency-dependent selection on interacting species (e.g., Dieckmann et al. 1995; Agrawal and Lively 2002) or select for one species to be less well matched to the other (Sasaki 2000; Nuismer and Otto 2005; Kopp and Gavrilets 2006; Yoder and Nuismer 2010). These dynamics are well documented in biological systems in which host defensive responses are activated by recognition of molecules expressed by parasites or pathogens (reviewed by Dybdahl et al. [2014]; Nuismer and Dybdahl [2016]).

Mutualistic interactions also require processes of recognition and signal exchange. Many brood pollinators respond to complex, host-species-specific floral scents that are not directly related to rewards offered by hosts (Svensson et al. 2005, 2016; Okamoto et al. 2007; Soler et al. 2011). Host plant volatiles also guide the colonizing queens of plant-protecting ant species and direct the activity of ants' patrols (Edwards et al. 2006b, 2007; Schatz et al. 2009). Legumes recognize and respond to signals and identifying surface proteins expressed by rhizobia and mycorrhizal fungi (Oldroyd et al. 2011). Immune-recognition responses help determine the assembly of animals' microbiomes (Pflughoeft and Versalovic 2012; Cullender et al. 2013; Mutlu et al. 2014). Such signaling and recognition factors in interacting mutualists may coevolve in very different ways from traits governing mutualistic performance, and coevolution of signals and responses to them may affect the coevolution of benefits exchanged.

We hypothesize that coevolving partner communication maintains variation in mutualism outcomes even as sanctions prevent the breakdown of mutualism. Here, we test this hypothesis with models of a mutualism in which outcomes are determined by (1) sanctions against noncooperative individuals, (2) recognition of signals that are separate from symbiont quality, or (3) sanctions against noncooperators paired with recognition of signals. We first present analytic models of allele frequency dynamics within a population of two interacting species, then use individual-based coevolutionary simulations to examine a wider range of parameters and to examine how coevolution in the different models shapes geographic variation as well as local diversity. We find that sanctions alone maintain mutualism without variation, while recognition alone maintains variation but not the mutualism.
Incorporating both sanctions and recognition can maintain the mutualism as well as variation in the outcomes of mutualists' interactions.

\section{Methods}

We model a mutualism with outcomes determined by sanctions against noncooperative partners, by recognition of partner signals separate from cooperation, or by both sanctions and recognition. The model is inspired by symbiotic mutualisms such as brood pollination (Pellmyr and Huth 1994; Jandér and Herre 2010) or nutrient symbioses like the legumerhizobium mutualism (Kiers et al. 2003), in which partly or fully free-living individuals of one species provide a benefit to members of another species, which provide rewards in return. As in many biological systems, the first of these species, the symbiont, is the one considered a potential "cheater," while the second species, the host, exerts sanctions against such individuals. For the purposes of this model, we consider that "sanctions" refer to any response by hosts such that they pay a reduced cost of hosting a symbiont that provides no benefit and deny the full benefit of symbiosis to that noncooperator. Many authors have used "partner choice" to refer to mutualists ceasing interaction with noncooperative individuals (e.g., Trivers 1971; Axelrod and Hamilton 1981; Foster et al. 2006); the sanctions in our model can encompass such partner choice (following, e.g., Kiers et al. 2003; Segraves 2003; Jandér and Herre 2016).

In all three models, we assume that hosts and symbionts encounter each other at random and interact and that each species $i$ receives a benefit $B_{i}$ and pays a cost $C_{i}$ of interaction. For both host and symbiont we assume that fitness is equal to $1+P_{j k}$, where $P_{j k}$ is the payout (i.e., net benefit) from the interaction of an individual with genotype $j$ interacting with a member of the other species with genotype $k$. Payout is determined by host and symbiont genotype and by the possible benefit $\left(B_{i}\right)$ and the cost $\left(C_{i}\right)$ of interaction. We assume that $B_{i}>C_{i}$, which restricts our analysis to conditions under which both partners can potentially receive a positive payout from the interaction.

\section{Analytic Models}

We first derive three analytic models of coevolving hosts and symbionts, which track allele frequencies in both species within a single population. Full details of model derivations and evaluation are available as Mathematica notebooks deposited in the Dryad Digital Repository: http://dx.doi.org /10.5061/dryad.p2s02 (Yoder and Tiffin 2017).

Host Sanctions. First, consider a model of host sanctions against noncooperative symbionts, in which symbiont cooperation and hosts' ability to sanction are each determined by 
a single biallelic locus. Symbionts with the $M$ allele at a "cooperation" locus cooperate; symbionts with the $m$ allele do not. Cooperative symbionts pay a cost of symbiosis, $C_{\mathrm{S}}$, and receive a benefit, $B_{\mathrm{S}}$, while noncooperative symbionts receive the benefit but pay no cost. A host interacting with a cooperative symbiont pays a cost of hosting symbionts, $C_{\mathrm{H}}$, and receives a benefit of symbiosis, $B_{\mathrm{H}}$. Hosts interacting with noncooperative symbionts receive no benefit but pay the cost unless they are able to sanction.

Hosts with the $H$ allele at a "sanctions" locus are able to stop interaction with a noncooperating symbiont with effectiveness $\omega$; hosts with the $h$ allele are not able to do so. The term $\omega$ determines the degree to which sanctioning hosts are able to avoid paying the costs of hosting noncooperating symbionts and deny them the benefit of symbiosis. If $\omega=1$, sanctioning hosts suffer no cost of hosting noncooperators and the noncooperators receive no benefit; if $\omega=0$, sanctions have no effect, so that hosts pay the full cost of symbiosis and noncooperators receive the full benefit (Axelrod and Hamilton 1981; Ohtsuki 2010). We do not include a separate term for a cost paid by hosts when they apply sanctions, but a cost is implicit if sanctions are less than fully effective $(\omega<1)$ and there is a nonzero cost of hosting symbionts $\left(C_{\mathrm{H}}>0\right)$. This parallels empirical systems in which sanctions cut off interaction after an initial investment, such as legumes that initiate nodulation with low-quality rhizobia only to reduce investment in less productive nodules (Kiers et al. 2006) or yuccas and figs that invest in flowers but abort them if they are too badly damaged by seed-feeding pollinators (Pellmyr and Huth 1994; Jandér and Herre 2010).

As noted above, host and symbiont fitness are equal to $1+P_{j k}$, where $P_{j k}$ is the payout from an individual with genotype $j$ interacting with a member of the other species with genotype $k$, as determined by the possible benefit $\left(B_{i}\right)$ and the cost $\left(C_{i}\right)$ of interaction to each species $i$ and by the effectiveness of sanctions $\omega$ (table 1 ). We can then derive the pergeneration change in the frequency of the host's $H$ allele,

$$
\Delta p_{\mathrm{H}}=p_{\mathrm{H}}\left(1-p_{\mathrm{H}}\right) \frac{\omega\left(1-p_{\mathrm{M}}\right) C_{\mathrm{H}}}{1+p_{\mathrm{M}} B_{\mathrm{H}}-\left[1-\omega p_{\mathrm{H}}\left(1-p_{\mathrm{M}}\right)\right] C_{\mathrm{H}}},
$$

and the symbiont's $M$ allele,

$$
\Delta p_{\mathrm{M}}=p_{\mathrm{M}}\left(1-p_{\mathrm{M}}\right) \frac{\omega p_{\mathrm{H}} B_{\mathrm{S}}-C_{\mathrm{S}}}{1+\left[1-\omega p_{\mathrm{H}}\left(1-p_{\mathrm{M}}\right)\right] B_{\mathrm{S}}-p_{\mathrm{M}} C_{\mathrm{S}}} .
$$

Partner Recognition. Next, consider a model of partner recognition, in which hosts interact only with symbionts expressing a signal compatible with the hosts's recognition genotype and symbiont signals are determined by a locus independent of the locus that determines whether symbionts cooper-
Table 1: Host and symbiont payouts under the model of host sanctions

\begin{tabular}{lll}
\hline & \multicolumn{2}{c}{ Host } \\
\cline { 2 - 3 } Symbiont & \multicolumn{1}{c}{$H$} & \multicolumn{1}{c}{$h$} \\
\hline Host payout: & & \\
$M$ & $B_{\mathrm{H}}-C_{\mathrm{H}}$ & $B_{\mathrm{H}}-C_{\mathrm{H}}$ \\
$m$ & $-(1-\omega) C_{\mathrm{H}}$ & $-C_{\mathrm{H}}$ \\
Symbiont payout: & & \\
$M$ & $B_{\mathrm{S}}-C_{\mathrm{S}}$ & $B_{\mathrm{S}}-C_{\mathrm{S}}$ \\
$m$ & $(1-\omega) B_{\mathrm{S}}$ & $B_{\mathrm{S}}$ \\
\hline
\end{tabular}

ate. This is essentially a "matching-alleles" infection-genetics model of the type used to study host-parasite interactions (Agrawal and Lively 2002; Nuismer 2017).

As in the sanctions model, symbionts cooperate if they have the $M$ allele at the cooperation locus and do not if they have the $m$ allele. Symbionts also carry either an $S$ allele or an $s$ allele at a "signaling" locus. Hosts have no ability to sanction noncooperating symbionts; instead, they carry either an $R$ allele or an $r$ allele at a "recognition" locus. Hosts with the $R$ allele initiate symbiosis only with symbionts carrying the $S$ signaling allele, and hosts with the $r$ allele initiate symbiosis only with symbionts carrying $s$. With no ability to sanction, hosts' payouts are determined solely by whether symbionts carrying compatible signaling alleles are also cooperative (table 2).

An exact analytic examination of equilibria in this model is impractical. However, if we assume that the costs and benefits of the interaction are small (Nuismer et al. 2010; Yoder and Nuismer 2010), that the effects of the symbiont cooperation $(M)$ and signaling $(S)$ loci are therefore not strongly epistatic, and that there is free recombination between symbiont loci, then alleles at these loci should remain in quasilinkage equilibrium (QLE) conditions (Barton and Turelli 1991; Kirkpatrick et al. 2002). With these assumptions, we can approximate change in the frequency of the host $R$ allele as

$$
\Delta p_{\mathrm{R}} \approx p_{\mathrm{R}}\left(1-p_{\mathrm{R}}\right)\left(2 p_{\mathrm{S}}-1\right)\left(p_{\mathrm{M}} B_{\mathrm{H}}-C_{\mathrm{H}}\right)
$$

that of the symbiont's $M$ allele as

$$
\Delta p_{\mathrm{M}} \approx p_{\mathrm{M}}\left(1-p_{\mathrm{M}}\right)\left[p_{\mathrm{S}}-p_{\mathrm{R}}\left(2 p_{\mathrm{S}}-1\right)-1\right] C_{\mathrm{S}}
$$

and that of the symbiont's $S$ allele as

$$
\Delta p_{\mathrm{S}} \approx p_{\mathrm{S}}\left(1-p_{\mathrm{S}}\right)\left(2 p_{\mathrm{R}}-1\right)\left(B_{\mathrm{S}}-p_{\mathrm{M}} C_{\mathrm{S}}\right) .
$$

We also calculate an approximate per-generation rate of change in linkage disequilibrium (LD) between alleles at the two symbiont loci. However, under our QLE assumptions, 
Table 2: Host and symbiont payouts under the model of partner recognition

\begin{tabular}{lll}
\hline & \multicolumn{2}{c}{ Host } \\
\cline { 2 - 3 } Symbiont & \multicolumn{1}{c}{$R$} & \multicolumn{1}{c}{$r$} \\
\hline Host payout: & $B_{\mathrm{H}}-C_{\mathrm{H}}$ & 0 \\
$M S$ & 0 & $B_{\mathrm{H}}-C_{\mathrm{H}}$ \\
$M s$ & $-C_{\mathrm{H}}$ & 0 \\
$m S$ & 0 & $-C_{\mathrm{H}}$ \\
$m s$ & & \\
Symbiont payout: & $B_{\mathrm{S}}-C_{\mathrm{S}}$ & 0 \\
$M S$ & 0 & $B_{\mathrm{S}}-C_{\mathrm{S}}$ \\
$M s$ & $B_{\mathrm{S}}$ & 0 \\
$m S$ & 0 & $B_{\mathrm{S}}$ \\
\hline$m s$ & &
\end{tabular}

LD does not contribute to the approximated change in host or symbiont allele frequencies, and the approximation for change in LD reveals that it will remain negligibly small (derivation in the appendix).

Sanctions with Recognition. Finally, consider a model in which hosts have loci for symbiont recognition (with alleles $R$ and $r$ ) and for sanctions ( $H$ and $h$ ) and symbionts have loci for signaling ( $S$ and $s$ ) and cooperation $(M$ and $m$ ). Hosts initiate symbiosis only with symbionts carrying a signaling allele compatible with the hosts' genotype at the recognition locus (i.e., $S$ with $R$ or $s$ with $r$ ), as in the partner-recognition model. However, hosts are also able to sanction if they carry the $H$ allele at the sanctioning locus, as in the host-sanctions model.

As in the host-recognition model, to develop a tractable model we assume that the costs and benefits of interaction are small, that there is no epistasis, and that there is free recombination between loci. The payout values for each possible combination of host and symbiont genotypes (table 3) then lead to the following approximations of change in the allele frequency at each locus in each species. For the host, these are

$\Delta p_{\mathrm{H}} \approx p_{\mathrm{H}}\left(1-p_{\mathrm{H}}\right)\left(1-p_{\mathrm{M}}\right)\left[1-p_{\mathrm{S}}+p_{\mathrm{R}}\left(2 p_{\mathrm{S}}-1\right)\right] \omega C_{\mathrm{H}}$,

$\Delta p_{\mathrm{R}} \approx p_{\mathrm{R}}\left(1-p_{\mathrm{R}}\right)\left(2 p_{\mathrm{S}}-1\right)\left\{p_{\mathrm{M}} B_{\mathrm{H}}-\left[\omega p_{\mathrm{H}}\left(1-p_{\mathrm{M}}\right)-1\right] C_{\mathrm{H}}\right\}$,

and for the symbiont

$\Delta p_{\mathrm{M}} \approx p_{\mathrm{M}}\left(1-p_{\mathrm{M}}\right)\left[1-p_{\mathrm{S}}-p_{\mathrm{R}}\left(1-2 p_{\mathrm{S}}\right)\right]\left(\omega p_{\mathrm{H}} B_{\mathrm{S}}-C_{\mathrm{S}}\right)$,

$\Delta p_{\mathrm{S}} \approx p_{\mathrm{S}}\left(1-p_{\mathrm{S}}\right)\left(2 p_{\mathrm{R}}-1\right)\left\{\left[1-\omega p_{\mathrm{H}}\left(1-p_{\mathrm{M}}\right)\right] B_{\mathrm{S}}-p_{\mathrm{M}} C_{\mathrm{S}}\right\}$.

As in the partner-recognition model, the approximations for change in allele frequencies do not include terms for LD between host loci or between symbiont loci, meaning that LD does not affect the approximated change in allele frequencies for either species - and the approximations for change in LD in both species indicate that LD will remain negligible (see the appendix).

\section{Individual-Based Simulations}

The approximations made to derive the analytic results may limit these models' generality, and evaluation of equilibrium conditions provides a limited perspective, given that few real biological communities are at an evolutionary equilibrium (Thompson 2013). Moreover, modeling dynamics in a single panmictic population misses the potential for divergence among geographically structured populations, which can be an important mechanism for diversification in coevolutionary systems (Nuismer et al. 1999; Thompson 2005, 2013; Yoder and Nuismer 2010). To account for a broader range of pa-

Table 3: Host and symbiont payouts under the model of recognition with sanctions

\begin{tabular}{lllll}
\hline & \multicolumn{5}{c}{ Host } \\
\cline { 2 - 5 } Symbiont & \multicolumn{1}{c}{$H R$} & \multicolumn{1}{c}{$h r$} & $h r$ \\
\hline Host payout: & $B_{\mathrm{H}}-C_{\mathrm{H}}$ & 0 & $B_{\mathrm{H}}-C_{\mathrm{H}}$ & 0 \\
$M S$ & 0 & $B_{\mathrm{H}}-C_{\mathrm{H}}$ & 0 & $B_{\mathrm{H}}-C_{\mathrm{H}}$ \\
$M S$ & $-(1-\omega) C_{\mathrm{H}}$ & 0 & $-C_{\mathrm{H}}$ & 0 \\
$m S$ & 0 & $-(1-\omega) C_{\mathrm{H}}$ & 0 & $-C_{\mathrm{H}}$ \\
$m s$ & & & & 0 \\
Symbiont payout: & $B_{\mathrm{S}}-C_{\mathrm{S}}$ & 0 & $B_{\mathrm{S}}-C_{\mathrm{S}}$ & $B_{\mathrm{S}}-C_{\mathrm{S}}$ \\
$M S$ & 0 & $B_{\mathrm{S}}-C_{\mathrm{S}}$ & 0 & 0 \\
$M s$ & $(1-\omega) B_{\mathrm{S}}$ & 0 & $B_{\mathrm{S}}$ & $B_{\mathrm{S}}$ \\
$m S$ & 0 & $(1-\omega) B_{\mathrm{S}}$ & 0 & \\
$m s$ & & & & \\
\hline
\end{tabular}


rameter space, such as stronger fitness effects of mutualism, to evaluate results at nonequilibrium conditions, and to examine the effects of geographic population structure and diversification, we constructed an individual-based simulation of coevolution between hosts and symbionts in a metapopulation of sites linked by migration (parameters are given in table 4; simulation scripts have been deposited in the Dryad Digital Repository: http://dx.doi.org/10.5061/dryad.p2s02; Yoder and Tiffin 2017).

The simulation follows the change in allele frequencies in 50 populations of $K_{i}$ haploid individuals of each species $i$, linked by migration at a rate of $m_{i}$. We chose parameters to ensure that the interaction would be commensal or mutualistic (all $B_{i} \geq C_{i}$ ) and that symbionts would usually have larger population sizes than hosts and experience greater benefits from symbiosis. These asymmetries are seen in many mutualistic symbioses. The simulation starts by randomly creating individuals' genotypes of one or two loci (depending on the model simulated) on the basis of starting allele frequencies drawn from an approximation of the allele frequency spectrum for a standard neutral coalescent model at equilibrium (Ganapathy and Uyenoyama 2009); note that this means that the simulations address not the conditions under which a new allele can invade a population but the expected fate of genetic variants that are already segregating in a population when coevolution begins. After creation of the starting populations, the simulation proceeds through a generational cycle of migration among populations, interaction between hosts and symbionts in each population, and finally mating within populations, with mating success determined by the outcome of the host-symbiont interactions.

Migration. A proportion $m_{i}$ of the individuals in each population are selected at random to join a global migrant pool, which are then distributed at random back among the populations.

Coevolutionary selection. Within each population, hosts interact with randomly drawn symbionts. All hosts interact with symbionts, while symbionts that are not drawn for in- teraction are lost from the population. Each individual's payout from the interaction is then determined by its genotype and the genotype of its host or symbiont, following one of the models outlined above. Finally, fitness is calculated for each individual as the payout of the interaction plus a value drawn at random from a normal distribution with a mean of 1 and a standard deviation of 0.1 . These fitness values are then used to determine the probability of reproduction in the next step.

Mating. Mating occurs between pairs of hermaphroditic individuals of each species. Pairs of individuals are drawn at random from the same population, with replacement, and with the probability of being drawn scaled by each individual's fitness value from the prior step. Each mating produces one offspring, with genotypes at each locus drawn from the parental genotypes. In two-locus species, recombination between loci occurs with probability $r_{i}$, and mutation from one allele to the alternate allele occurs with probability $\mu_{i}$ for each locus. Mating continues until $K_{i}$ offspring are created, at which time the offspring replace their parents to begin the next generation.

We ran 500 simulations for each of the three models as well as 500 simulations in which hosts and symbionts do not interact, which provide an expectation for evolution in the absence of the mutualism. Unless stated otherwise, we summarized simulation results after 1,000 generations, well past the time at which among-site variation in allele frequencies stabilized.

\section{Results \\ Analytic Models}

We solved for equilibria in each of the three analytic models (sanctions only, recognition only, and sanctions with recognition) to identify conditions that maintain variation in host or symbiont loci and maintain mutualism (i.e., the frequency of symbiont cooperation, $p_{\mathrm{M}}>0$ ). Full details of these analyses are given in Mathematica notebooks available

Table 4: Parameter values for the individual-based simulations

\begin{tabular}{lll}
\hline Parameter & \multicolumn{1}{c}{ Host } & \multicolumn{1}{c}{ Symbiont } \\
\hline For metapopulation structure: & & \\
$\quad K$, per-site population size & $U(20,200)$ & $U(200,2,000)$ \\
$\quad m$, among-site migration rate & $U(0, .5)$ & $U(0, .05)$ \\
For interaction payouts: & & \\
$\quad C$, cost of symbiosis & $U(.01, .1)$ & $U(.001, .1)$ \\
$B$, benefit of symbiosis & $C_{\mathrm{H}}+U(.01, .1)$ & $C_{\mathrm{S}}+U(.01, .1)$ \\
$\omega$, effectiveness of sanctions & $U(.01,1)$ & $U(.01,1)$ \\
For genetics: & & $U(0, .5)$ \\
$r$, recombination rate & $U(0, .5)$ & $10^{-6}$ \\
$\mu$, mutation rate & $10^{-6}$ & $U(\mathrm{~m}, \mathrm{n})$ \\
\hline
\end{tabular}

Note: Parameters are either point values or drawn from a uniform distribution with range $U(\min , \max )$. 
in the Dryad Digital Repository: http://dx.doi.org/10.5061 /dryad.p2s02 (Yoder and Tiffin 2017).

Sanctions. The sanctions model has no stable equilibria that maintain variation in either sanctions or cooperation (fig. 1). There are locally unstable equilibria when $p_{\mathrm{M}}=0$ and $p_{\mathrm{H}}$ is equal to either 1 or 0 and when $p_{\mathrm{M}}=1$ at any value of $p_{\mathrm{H}}$. Although variation is not maintained at either the sanctions or the cooperation locus, the rates of change in the frequencies of sanctioning and cooperation alleles are very low whenever $p_{\mathrm{M}}$ or $p_{\mathrm{H}}$ is near 1 , meaning that it may take considerable time for these alleles to become fixed.

Partner Recognition. In the partner-recognition model there are locally unstable equilibria that maintain variation, with cyclical dynamics, at the recognition and signaling loci $\left(p_{\mathrm{R}}=\right.$ $\left.p_{\mathrm{s}}=0.5\right)$, but only when the symbiont cooperation allele $(M)$ is fixed or lost (fig. 2). There are also unstable equilibria that maintain variation in cooperation (i.e., $M$ is at intermediate frequency), but only when the host's recognition locus and the symbiont's signaling locus are fixed for incompatible alleles. In other words, the system can maintain variation in recognition, but only when that recognition has no consequences for fitness, and it can maintain variation for cooperation, but only when symbiosis is never initiated. Under these conditions, variation maintained at mutualism-related loci is effectively neutral and would be lost via drift in finite populations.

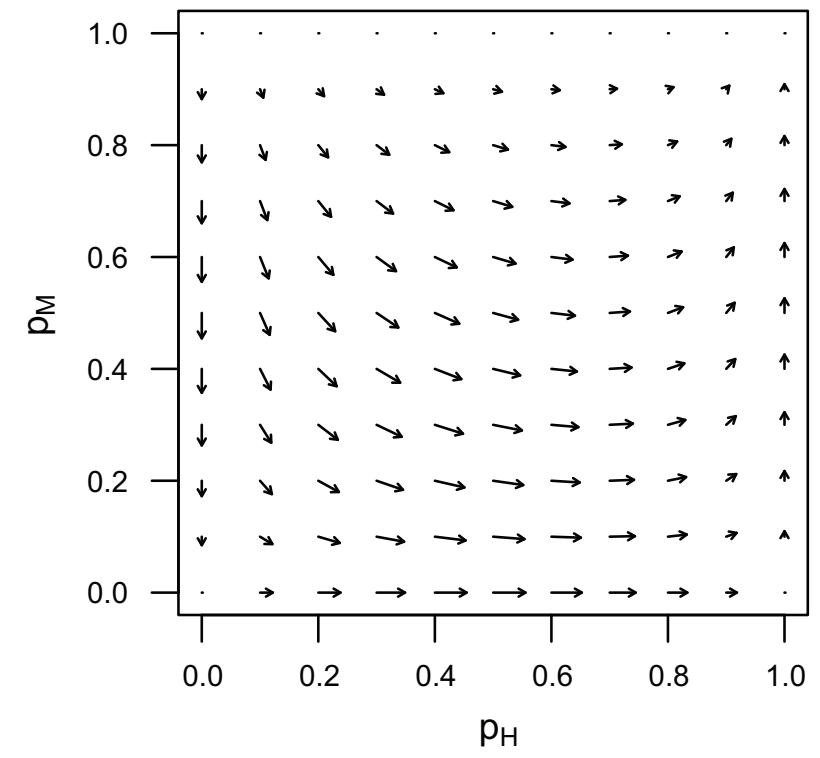

Figure 1: Dynamics of the host-sanctions model. Vector-field plot indicating magnitude and direction of change in the frequency of host sanctions $\left(p_{\mathrm{H}}\right)$ and symbiont cooperation $\left(p_{\mathrm{M}}\right)$ alleles at given starting frequencies, with $C_{\mathrm{H}}=C_{\mathrm{S}}=0.25, B_{\mathrm{H}}=B_{\mathrm{S}}=0.5$, and $\omega=0.75$.

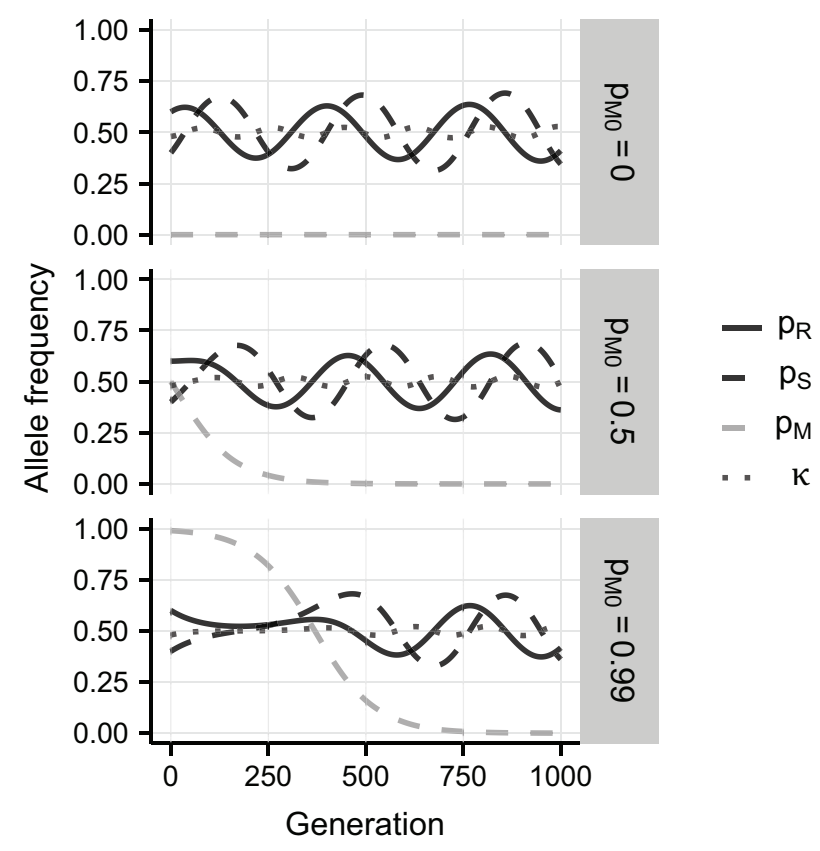

Figure 2: Dynamics of partner recognition. Allele frequencies over time at host recognition $\left(p_{\mathrm{R}}\right.$, solid lines) and symbiont signaling $\left(p_{\mathrm{S}}\right.$, dashed black lines) loci, allele frequency at the symbiont cooperation locus ( $p_{\mathrm{M}}$, dashed gray lines), and host-symbiont compatibility ( $\kappa$, dotted lines), with initial frequency of the symbiont cooperation allele $p_{\mathrm{M} 0}=0, p_{\mathrm{M} 0}=0.5$, or $p_{\mathrm{M} 0}=0.99$ and with $C_{\mathrm{H}}=C_{\mathrm{S}}=0.025$ and $B_{\mathrm{H}}=B_{\mathrm{S}}=0.05$.

Variation at signaling loci is maintained by inverse frequency-dependent selection when the cooperation allele is lost from the population $\left(p_{\mathrm{M}}=0\right)$. However, this is not surprising, given that when $p_{\mathrm{M}}=0$ the system is effectively a host-parasite system; such systems have been repeatedly shown to maintain variation, with a two-allele system determining host recognition (Dieckmann et al. 1995; Agrawal and Lively 2002). We can examine these dynamics in terms of host-symbiont compatibility, or the probability that a randomly drawn host and symbiont will carry compatible recognition and signaling alleles, defined as $\kappa=p_{\mathrm{R}} p_{\mathrm{S}}+(1-$ $\left.p_{\mathrm{R}}\right)\left(1-p_{\mathrm{S}}\right)$. This probability remains close to 0.5 even as recognition and signaling allele frequencies cycle (fig. 2).

Perhaps the most important feature of the model of partner recognition is that change in the frequency of the symbiont cooperation allele, $\Delta p_{\mathrm{M}}$, is less than or equal to 0 for all reasonable parameter values (eq. [4]; see also the "recognition" Mathematica notebook in the Dryad Digital Repository: http://dx.doi.org/10.5061/dryad.p2s02; Yoder and Tiffin 2017). That is, there is no condition under which a cooperative symbiont allele $(M)$ will increase in frequency. This means that partner recognition alone cannot select for greater frequency of cooperation, from any starting frequency (fig. 2). 
Sanctions with Recognition. The model of partner recognition with host sanctions has equilibria that maintain variation at both the host recognition and the symbiont signaling loci. Still, the only locally stable equilibria at which hosts or symbionts maintain variation in sanctioning or cooperation also have hosts and symbionts fixed for incompatible recognition/signaling alleles - conditions ensuring that symbiosis is never initiated. Unstable equilibria exist where there is variation in host sanctions or symbiont cooperation without complete loss of host-symbiont compatibility and where cyclical dynamics can occur at the host recognition and symbiont signaling loci (fig. 3, middle). These depend on starting allele frequencies, the cost and benefit of mutualism to each species, and particularly the effectiveness of sanctions.

If sanctions are not very effective (i.e., $\omega$ is low), then the symbiont cooperation allele $M$ may be lost even as the host sanctions allele $H$ become fixed; loss of cooperative symbionts leads to inverse frequency-dependent cycling at the host recognition and symbiont signaling loci, as seen in a host-pathogen model (fig. 3, top). With more effective sanctions, symbiont cooperation can be maintained at low frequency, while inverse frequency-dependent cycles at the signaling and recognition loci still occur-reflecting the fact the symbiosis is, on average, detrimental to host fitness so long as fewer than half of symbionts are cooperative (fig. 3, middle).
When sanctions are sufficiently effective, variation can be maintained at the host sanctions locus once symbiont cooperation is fixed and the recognition/signaling loci become fixed for compatible alleles (i.e., $R$ and $S$; fig. 3, bottom). This parallels results from the model of host sanctions alone (fig. 1), in which fixation of symbiont cooperation reduces $\Delta p_{\mathrm{H}}$ to 0 (eq. [1]). Indeed, when the signaling and recognition loci are fixed for compatible alleles $(\kappa=1)$, the model of sanctions with recognition behaves like the model of sanctions alone.

Meanwhile, the relative fitness of each symbiont signaling allele depends not only on the frequency of host recognition alleles $\left(p_{\mathrm{R}}\right)$ but also on the frequency of symbiont cooperation $\left(p_{\mathrm{M}}\right)$, the frequency of sanctioning hosts $\left(p_{\mathrm{H}}\right)$, and the degree to which sanctions reduce the fitness of noncooperating symbionts $(\omega)$. This is apparent from the approximate expression for change in the frequency of the symbiont signaling allele, $\Delta p_{\mathrm{S}}$, which has an unstable equilibrium when $p_{\mathrm{H}}=1$ and $C_{\mathrm{S}} / B_{\mathrm{S}}=1-\omega\left(1-p_{\mathrm{M}}\right)$ (eq. [9]).

Host-symbiont compatibility, $\kappa$, increases most rapidly when most symbionts are cooperative, when sanctioning hosts are more common, and when hosts have near-maximum variation at the recognition locus $\left(p_{\mathrm{R}}\right.$ is near 0.5$)$ but symbionts are nearly fixed for one signaling allele (fig. 4, dark-shaded regions). It decreases most rapidly when hosts are mostly un-

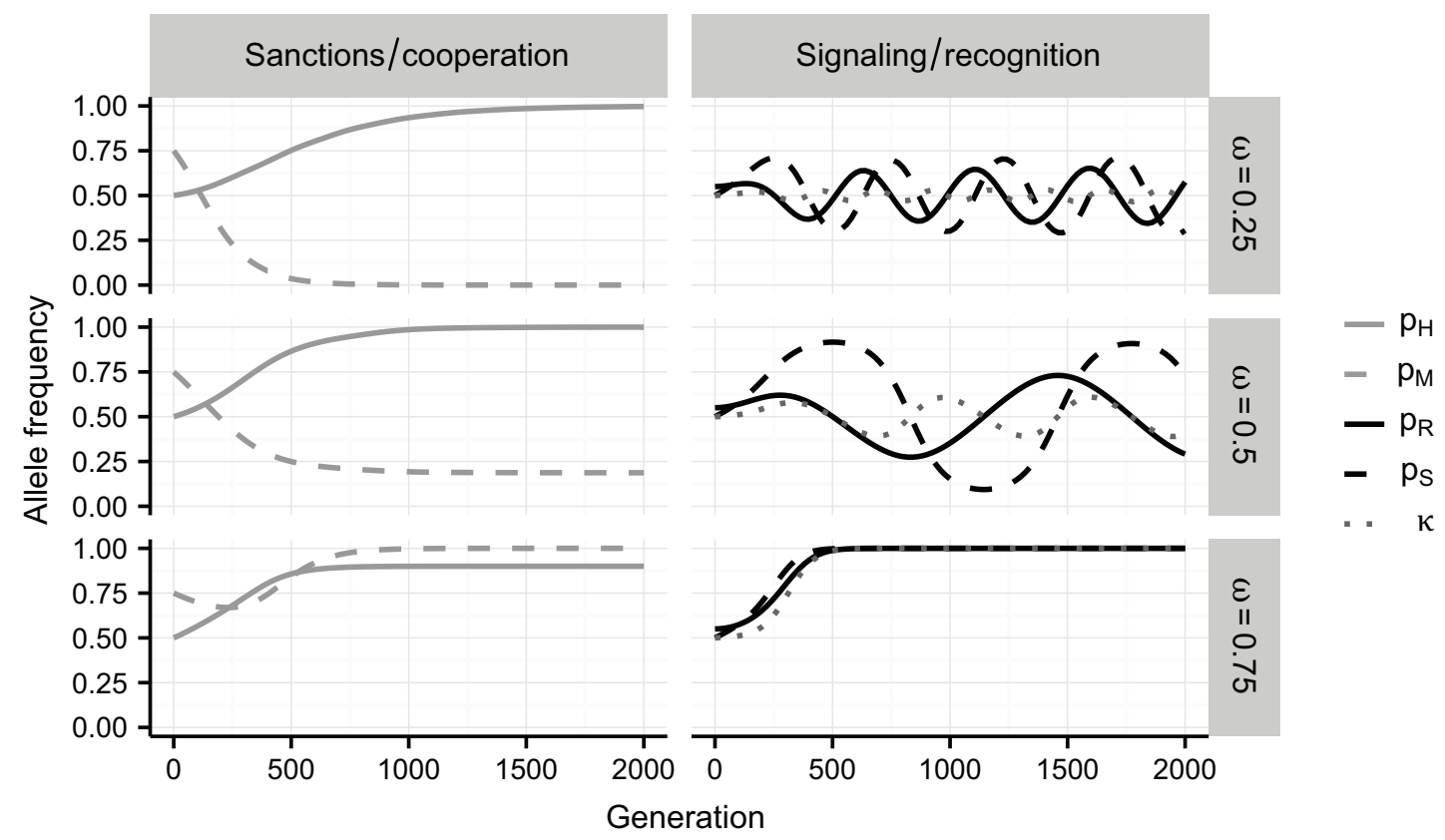

Figure 3: Dynamics of host sanctions with partner recognition. Frequency of the host sanctions allele ( $p_{\mathrm{H}}$, left, solid lines) and symbiont cooperation allele $\left(p_{\mathrm{M}}\right.$, left, dashed lines) or frequency of the host recognition allele ( $p_{\mathrm{R}}$, right, solid lines) and symbiont signaling allele $\left(p_{\mathrm{R}}\right.$, right, dashed lines) with host-symbiont compatibility ( $\kappa$, right, dotted lines), when the effectiveness of sanctions $\omega=0.25$ (top), 0.5 ( $m i d-$ dle), or 0.75 (bottom). For all scenarios, the initial frequencies of the host sanctions allele $p_{\mathrm{H}}=0.5$, host recognition allele $p_{\mathrm{R}}=0.55$, symbiont cooperation allele $p_{\mathrm{M}}=0.75$, and symbiont signaling allele $p_{\mathrm{S}}=0.5 ; C_{\mathrm{H}}=C_{\mathrm{S}}=0.025$; and $B_{\mathrm{H}}=B_{\mathrm{S}}=0.05$. 


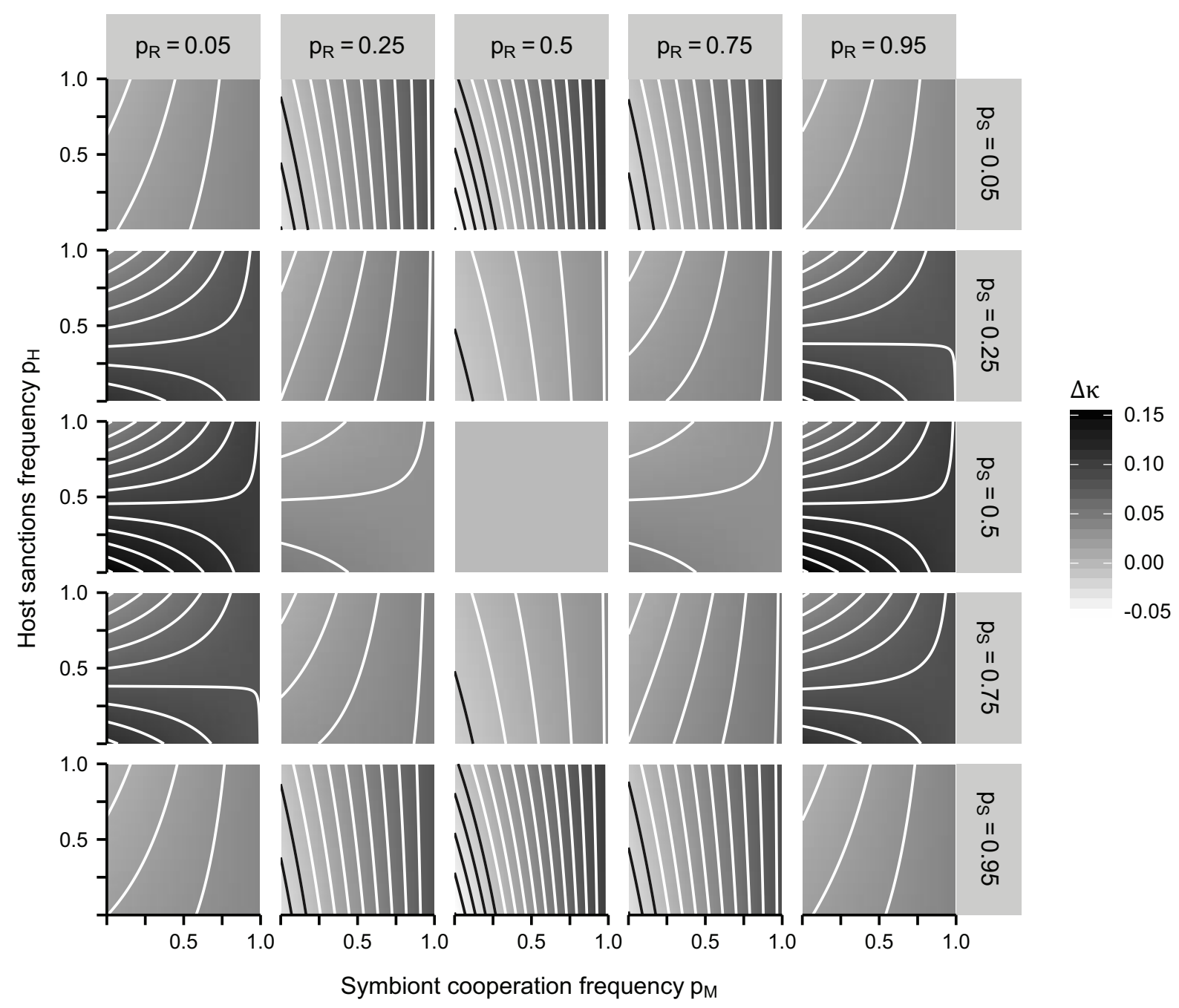

Figure 4: Analytical results showing per-generation change in host-symbiont compatibility, $\Delta \kappa$, for different starting frequencies of the symbiont cooperation allele, $p_{\mathrm{M}}$, and host sanctions allele, $p_{\mathrm{H}}$, and for different starting frequencies of the host recognition allele, $p_{\mathrm{R}}$, and symbiont signaling allele, $p_{\mathrm{s}}$. Darker shading indicates greater values of $\Delta \kappa$; contour lines are at intervals of 0.01 , with white lines indicating values of $\Delta \kappa>0$. For all panels $\omega=0.75, B_{\mathrm{S}}=B_{\mathrm{H}}=0.75$, and $C_{\mathrm{S}}=C_{\mathrm{H}}=0.25$.

able to sanction, cooperative symbionts are at a lower frequency $\left(p_{\mathrm{M}}<0.5\right)$, and hosts mostly carry a recognition allele compatible with the more common symbiont allele (fig. 4 , light-shaded regions).

\section{Individual-Based Simulations}

Sanctions. After 1,000 generations, individual-based simulations of the sanctions model ended with the host sanctioning allele at a frequency significantly higher than expected from neutral simulations (fig. $5 A$; $t$-test on arcsine-transformed values: $\left.p<1 \times 10^{-6}\right)$. This is consistent with the predictions of the analytic model (fig. 1). Still, the sanctioning allele, $H$, became fixed in only $21 \%$ of simulations, and there was considerable overlap in the range of frequencies seen for the sanctioning allele and that for neutral alleles. Sanctioning hosts were more common when costs of symbiosis for the hosts were greater (Spearman's $\rho_{p_{\mathrm{H}}, C_{\mathrm{H}}}=0.25, p<1 \times$ $\left.10^{-6}\right)$ and when the benefits of symbiosis were greater $\left(\rho_{p_{\mathrm{B}}, B_{\mathrm{B}}}=\right.$ $0.15, p<.001)$.

Sanctions resulted in higher symbiont cooperation (fig. $5 \mathrm{~A}$ ), again consistent with the predictions of the analytic model (fig. 1). The cooperation allele, $M$, rose to significantly higher frequency than neutral alleles ( $t$-test: $\left.p<1 \times 10^{-6}\right)$ and became fixed in $59 \%$ of sanctions simulations. However, cooperation was lost in $21 \%$ of simulations. Cooperative symbionts were less common when the cost of symbiosis was higher $\left(\rho_{p_{\mathrm{N}}, C_{\mathrm{S}}}=-0.20, p<1 \times 10^{-5}\right)$; in contrast, cooper- 

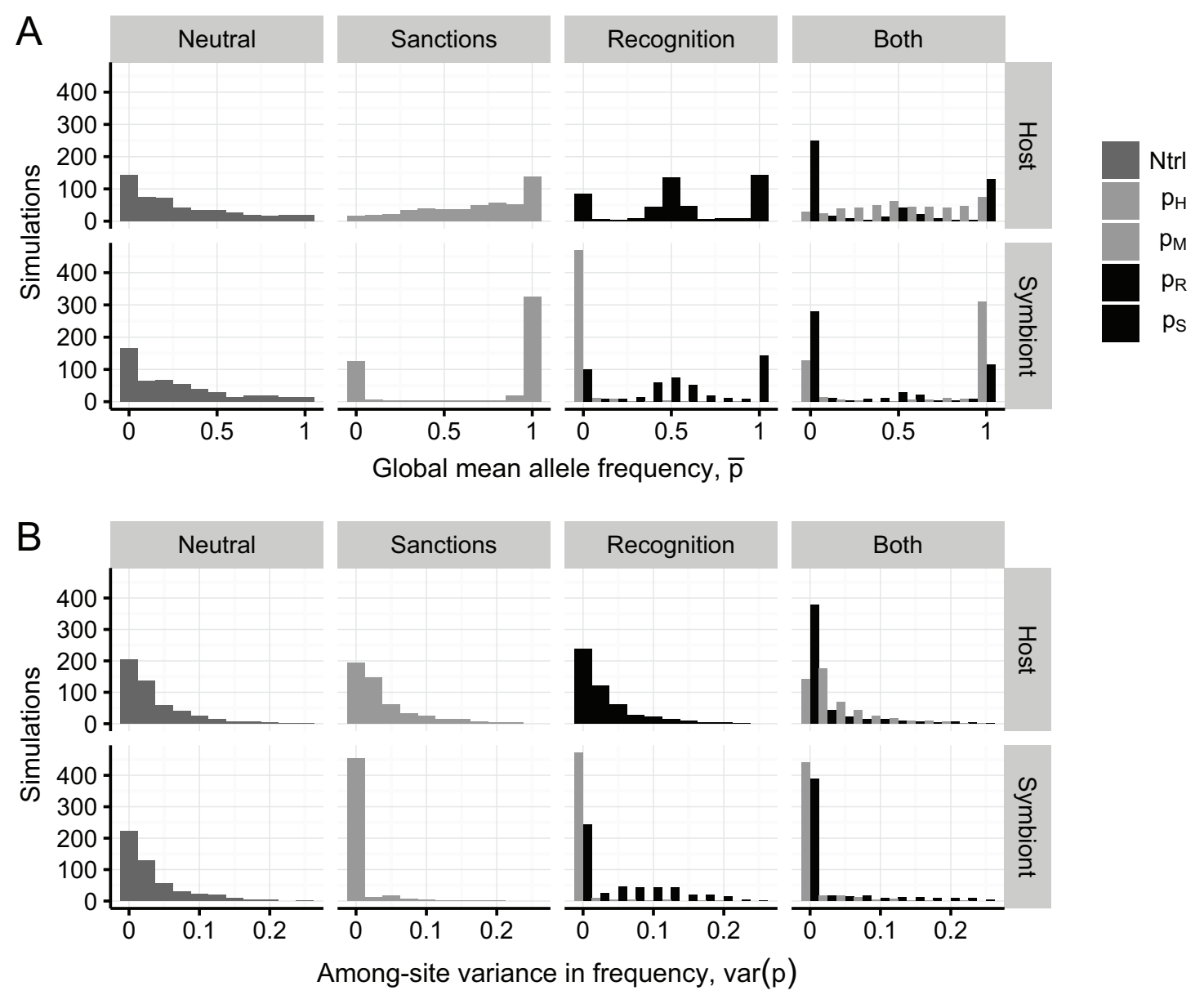

Figure 5: Mean within-population allele frequencies $(A)$ and among-site variation in local allele frequency $(B)$ after 1,000 generations of coevolution with no interaction (neutral) or with each of the three models of host-symbiont interaction. Results are from 500 replicate simulations with parameters given in table 4.

ative symbionts were more common when the benefits were higher $\left(\rho_{p_{\mathrm{M}}, B_{\mathrm{S}}}=0.23, p<1 \times 10^{-6}\right)$ and when host sanctions were more effective $\left(\rho_{p_{\mathrm{M}}, \omega}=0.53, p<1 \times 10^{-6}\right)$.

To examine geographic differentiation among sites, we calculated the among-site variance in allele frequencies for each replicate simulation (fig. $5 B$ ). In simulations of the sanctions model, among-site variance in the frequency of the host sanctions allele was very similar to that seen for neutral simulations. The symbiont cooperation locus, however, had much lower among-site variation $\left(\operatorname{Var}\left(p_{\mathrm{M}}\right)=0\right.$ in $80 \%$ of simulations) than neutral loci $(\operatorname{Var}(p)=0$ in $20 \%$ of neutral simulations), reflecting the high proportion of simulations in which symbiont cooperation became fixed (fig. $5 A$ ).

Partner Recognition. In simulations of partner recognition alone, symbiont cooperation was lost in the vast majority of simulations (79\%; fig. $5 A$ ), as predicted by the analytic model (fig. 2). Consistent with the cyclical dynamics predicted by the analytic model, host recognition alleles were more likely to be at intermediate frequencies than neutral alleles $(0.4<$ $p_{\mathrm{R}}<0.6$ in $42 \%$ of simulations, vs. $12 \%$ for neutral alleles), and the same was true for symbiont signaling alleles $(0.4<$ $p_{\mathrm{S}}<0.6$ in $28 \%$ of simulations, vs. $10 \%$ for neutral alleles). Signaling and recognition alleles were also often fixed or lost, but they could resume cyclical dynamics when variation was reintroduced by mutation (fig. 6).

Patterns of among-site variation at the symbiont signaling and host recognition loci were broadly similar to those seen for neutral loci (fig. 5B). However, because the symbiont cooperation allele was so often lost, among-site variation in the frequency of the symbiont cooperation allele was much lower than that seen for either the symbiont signaling alleles or neutral alleles $\left(\operatorname{Var}\left(p_{\mathrm{M}}\right)=0\right.$ in $79 \%$ of simulations, $\operatorname{Var}\left(p_{\mathrm{S}}\right)=$ 0 in $42 \%$, and $\operatorname{Var}(p)=0$ in $22 \%)$. 


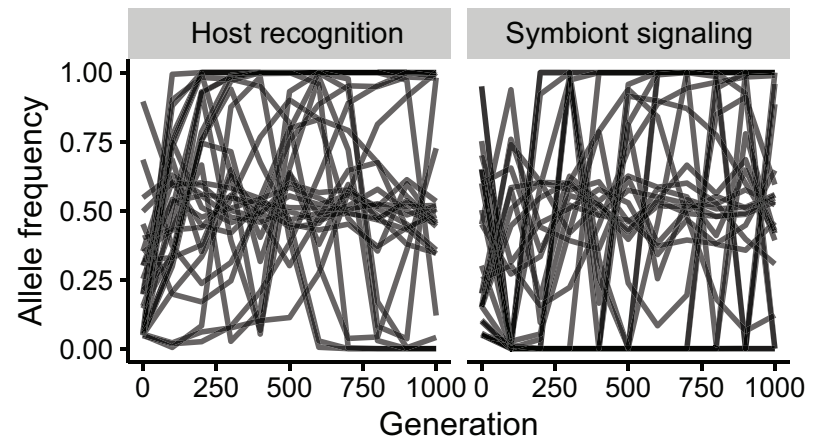

Figure 6: Cyclical dynamics in individual-based simulations of recognition. Plots of allele frequency over time at the host recognition locus $\left(p_{\mathrm{R}} ;\right.$ left $)$ and symbiont signaling locus $\left(p_{\mathrm{s}} ;\right.$ right $)$, in a sample of 30 replicate simulations.

Sanctions with Recognition. Simulations of sanctions with recognition resulted in, on average, somewhat lower frequency of sanctioning hosts than simulations of sanctions alone ( $t$-test on arcsine-transformed data: $p<1 \times 10^{-6}$ ) and were less likely to have sanctions fixed $\left(p_{\mathrm{H}}=1\right.$ in $11 \%$ of simulations of sanctions with recognition, compared to $21 \%$ with sanctions alone). As in simulations of sanctions alone, sanctioning hosts were more common when the cost of symbiosis was higher $\left(\rho_{p_{\mathrm{H}}, C_{\mathrm{H}}}=0.36, p<1 \times 10^{-6}\right)$ and when the benefits were greater $\left(\rho_{p_{\mathrm{H}}, B_{\mathrm{H}}}=0.21, p<1 \times 10^{-5}\right)$.

The fate of symbiont cooperation in simulations of sanctions with recognition was also similar to results from the simulations of sanctions alone. In $56 \%$ of simulations the cooperation allele went to fixation, though it was lost in $21 \%$. Also as in the simulations of sanctions alone, cooperative symbionts were more common when costs of symbiosis were lower $\left(\rho_{p_{\mathrm{M}}, C_{\mathrm{s}}}=-0.22, p<1 \times 10^{-6}\right)$, when benefits were greater $\left(\rho_{p_{\mathrm{M}}, B_{\mathrm{S}}}=0.20, p<1 \times 10^{-5}\right)$, and when host sanctions were more effective $\left(\rho_{p_{\aleph}, \omega}=0.61, p<1 \times 10^{-6}\right)$.

The frequency of host recognition alleles was strongly and positively correlated with the frequency of symbiont signaling alleles at all time points (at generation 1,000, $\rho=0.80$ for $p_{\mathrm{R}}$ and $p_{\mathrm{S}}, p<1 \times 10^{-6}$ ), and recognition and signaling alleles were at intermediate frequency in fewer simulations of sanctions with recognition $\left(0.4<p_{\mathrm{R}}<0.6\right.$ in $12 \%$ of simulations; $0.4<p_{\mathrm{S}}<0.6$ in just $9 \%$ ), compared to simulations of recognition alone. This is consistent with hosts and symbionts converging on compatible signaling and recognition alleles and maintaining them at high frequency - something also seen in the analytical model when sanctions were effective. Indeed, in simulations of sanctions with recognition, host-symbiont compatibility $(\kappa)$ was generally much higher than in the model of recognition alone (fig. 7; $t$-test on arcsine-transformed values: $p<1 \times 10^{-6}$ ).

In simulations of sanctions with recognition, the two mechanisms of interaction (i.e., sanctions/cooperation and recognition/signaling) evolved in response to each other, as predicted by the analytic model (figs. 3,4 ). Hosts and symbionts were more compatible when there were more sanctioning hosts at early time points in the simulation, but this correlation decreased over time, possibly because of fixation of the sanctioning allele in many replicates (tests on arcsinetransformed values: at generation 100 , Spearman's $\rho_{p_{\mathrm{H}, ~}}=$ $0.25, p<1 \times 10^{-6}$; at generation 500, $\rho_{p_{\mathrm{H}}, \kappa}=0.17, p=$ .001 ; at generation $1,000, \rho_{p_{\mathrm{H}}, \kappa}=0.05, p=.30$ ).

Notably, simulations of sanctions with recognition maintained significantly more among-site variation at the sanctions locus than simulations of sanctions alone ( $t$-test on arcsine-transformed values: $p=.005$ ) and maintained much less among-site variation at the host recognition locus than simulations of recognition alone $\left(t\right.$-test: $\left.p<1 \times 10^{-6}\right)$. Sim-

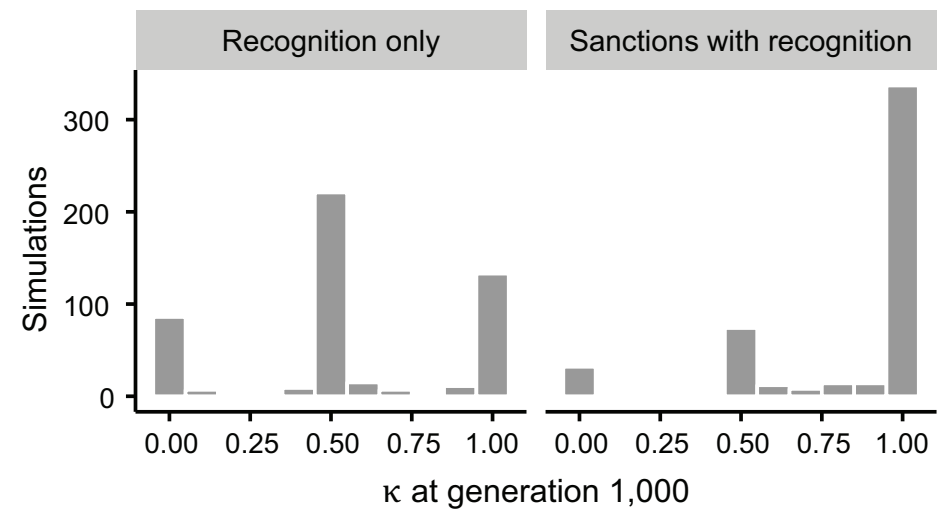

Figure 7: Host-symbiont compatibility, $\kappa$, after 1,000 generations of coevolution in simulations of recognition alone (left) or of sanctions with recognition (right). 
ulations of sanctions alone and sanctions with recognition both resulted in very low among-site variation at the symbiont cooperation locus, with $\operatorname{Var}\left(p_{\mathrm{M}}\right)=0$ in $76 \%$ and $70 \%$ of simulations, respectively.

\section{Discussion}

Variation in the quality of mutualistic partners is widely observed in natural systems (Pellmyr and Huth 1994; Herre and West 1997; Holland and Fleming 1999; Simms and Taylor 2002; Ness et al. 2006; Heath and Tiffin 2009; Hoeksema 2010; reviewed by Heath and Stinchcombe [2014]), in spite of the fact that mechanisms that stabilize mutualisms against cheating should remove such variation over time (Axelrod and Hamilton 1981; Doebeli and Knowlton 1998; West et al. 2002b; Kopp and Gavrilets 2006; Yoder and Nuismer 2010). Genetic variation can be maintained in the face of selection by mutation-selection balance (Foster et al. 2006) or by drift and migration among spatially structured populations (Thompson 2013; Heath and Stinchcombe 2014), but none of the forms of coevolutionary selection typically expected between mutualists are expected to maintain variation.

Our model of symbiotic mutualism in which hosts recognize symbiont signals and sanction noncooperative symbionts shows how coevolutionary selection between mutualists can both stabilize mutualism and maintain variation in its outcomes. Neither sanctions nor partner recognition alone maintains mutualism and variation in mutualism outcomes. However, in a model that includes both mechanisms, variation can be maintained, either because hosts and symbionts vary in sanctioning ability and cooperation or because they vary in their signaling/recognition compatibility (fig. 3). Our individual-based simulations corroborate the prediction from the analytic model that the sanctions and recognition systems interact by altering the coevolutionary conditions each genetic system faces (figs. 5, 7).

\section{Sanctions versus Recognition, Solo and in Concert}

Like previous models (Trivers 1971; Axelrod and Hamilton 1981; Bull and Rice 1991; West et al. 2002a, 2002b; Foster and Wenseleers 2006), ours finds that host sanctions can maintain cooperative symbionts at high frequency (figs. 1, 5). The advantage of noncooperation may cause the frequency of cooperative symbionts to decrease, but lower frequency of cooperation increases the relative fitness of sanctioning hosts - and once sanctions are sufficiently common, the frequency of cooperative symbionts increases to fixation (fig. 1).

On the other hand, when partner signals and cooperation are determined by unlinked loci, partner recognition alone is unable to select for greater frequency of cooperative symbionts (eq. [4]), and when cooperative symbionts are lost, selection favors hosts compatible with whichever symbiont signaling allele is less common (fig. 2). Because hosts gain no benefit from the symbiosis, this situation is effectively the loss of mutualism, and it creates coevolutionary cycles in the frequency of signaling and recognition alleles (figs. 2, 6), similar to what is seen in host-pathogen systems (Dieckmann et al. 1995; Agrawal and Lively 2002; M'Gonigle and Otto 2011).

In contrast to these simpler systems, when hosts both selectively initiate symbiosis based on recognition of symbiont signals and sanction noncooperative symbionts, the system can maintain variation at the host sanctions and recognition loci and at the symbiont cooperation and signaling loci (fig. 3, middle). However, this occurs only when sanctions have intermediate effectiveness; if sanctions are less effective, the same starting conditions and interaction payout result in loss of cooperation (fig. 3, top), whereas if sanctions are stronger, symbiont cooperation becomes fixed, and recognition and signaling loci fix for compatible alleles (fig. 3, bottom). Once cooperation is fixed, the host sanctioning allele is effectively neutral, and variation at that locus is expected to be lost to drift. If there were a cost to simply maintaining the ability to sanction, we might expect that sanctioning hosts would become less common again, creating an opportunity for noncooperative symbionts to reemerge via mutationcreating cyclical dynamics over longer time periods than we consider here. Because fixation of symbiont cooperation eliminates the source of selection favoring sanctioning, it has been proposed that reintroduction of noncooperative partners, or interaction with multiple partner species that vary in their cooperativeness, is necessary to maintain sanctions in mutualist populations over the long term (Foster et al. 2006).

Our simulations of sanctions with recognition show somewhat less frequent fixation of the host sanctioning allele and more among-site variation in its frequency than simulations of sanctions alone (fig. 5). These outcomes are connected to the fact that when hosts can sanction noncooperative symbionts, there is less selective advantage to avoiding symbiosis, and hosts and symbionts converge on compatible recognition and signaling alleles (fig. 7). These results recall those from models of mutualism based on economic contract theory, which propose that sanctioning is often best understood not as a specific adaptation to minimize the cost of interaction with noncooperative partners (Weyl et al. 2010; Archetti et al. 2011a,2011b) but as preexisting characteristics of the mutualists that provide partner-fidelity feedback by positively responding to cooperative symbionts (Archetti et al. 2011a Frederickson 2013). Under this thinking, floral abortion in response to pollinator overexploitation in brood pollination mutualisms is a repurposing of plants' response to floral damage, and legumes' reduced allocation to underproductive root nodules may be due to adaptations for root growth in soil with heterogenous nutrient content (Pellmyr and Huth 1994; Kiers et al. 2006; Weyl et al. 2010; Batstone et al. 2017). In 
our model, interaction with symbionts of varying quality leads to higher frequency, and often fixation, of sanctioning hosts (figs. 3, 5A). High frequency of sanctioning hosts then relaxes selection for host recognition alleles that prevent symbiosis, resulting in higher host-symbiont compatibility (figs. 4, 7). This recapitulates the result of Archetti et al. (2011a) that hosts offering the right "terms" to symbionts need not screen for cooperative individuals before initiating the interaction (in our model, the "terms" offered to symbionts would be that hosts will not sanction if symbionts cooperate).

Although few well-studied mutualisms involve two haploid partners, as in our models, we do not believe that relaxing this assumption would change our conclusions. M'Gonigle and Otto (2011) modeled the effect of host and symbiont ploidy in a matching-alleles model similar to the system we consider and found that diploid hosts were better able to recognize and resist both haploid and diploid parasites. This suggests that a diploid version of our partner-recognition model would see hosts better able to evade symbiosis when cooperative symbionts are rare, but such evasion does not select for more cooperative symbionts (fig. 2). A diploid model of host sanctions could allow more continuous variation in sanctioning effectiveness and symbiont cooperation, but the fundamental dynamic of sanctions selecting for more cooperative symbionts should remain (figs. 1, 3).

\section{Cooperation and Communication in Mutualism}

Our results suggest that multiple genetic mechanisms, which may experience very different forms of coevolutionary selection, may contribute to the evolution of cooperating species. Evaluating this prediction will require experiments that explicitly separate the exchange of benefits from the initiation of a mutualism (e.g., Regus et al. 2014; Althoff 2016; Powell and Doyle 2016). Population genetic studies that test for different signals of selection at loci with different roles in mutualism may also provide insight into the long-term selection that has acted on different stages of an interaction (e.g., Paape et al. 2013; Bonhomme et al. 2015; Yoder 2016).

There is evidence in many mutualisms for communication between partners that is based on traits separate from the rewards provided to (or withheld from) those mutualists (Svensson et al. 2005, 2016; Edwards et al. 2006a; Okamoto et al. 2007; Soler et al. 2011). The system in which the relationship between partner signals and response to partner performance is best understood may be the symbiotic mutualism of legumes and nitrogen-fixing rhizobial bacteria. Legumes sanction ineffective rhizobia (Kiers et al. 2003, 2006; Regus et al. 2014) or preferentially allocate resources to nodules hosting effective rhizobia (Heath and Tiffin 2009; Batstone et al. 2017), but they also respond to molecular signals from rhizobia as they establish symbiosis (Triplett and Sadowsky 1992; Oldroyd et al. 2011). At the level of quantitative pheno- types, host-rhizobium compatibility is at least partly independent of variation in mutualism outcomes (Triplett and Sadowsky 1992; Béna et al. 2005; Heath and Tiffin 2009; Grillo et al. 2016; Powell and Doyle 2016).

Members of legume gene families associated with pathogen recognition are also implicated in legume-rhizobium compatibility (Yang et al. 2010; Young et al. 2011), and some legume genes with roles in the symbiosis show elevated nucleotide diversity and geographic differentiation consistent with frequency-dependent selection (Yoder 2016). By contrast, rhizobial genes producing nodule initiation factors and type III effector genes, both of which can be recognized by hosts, have reduced diversity (Bailly et al. 2006; Kimbrel et al. 2013). Another complicating factor is that many rhizobia species have genes involved in signaling and nitrogen fixation physically linked in a "symbiosis island" (e.g., Sullivan and Ronson 1998; Laguerre et al. 2001; Parker 2012), which might reduce the opportunity for separate evolution of signaling and cooperation. Still, there are examples of rhizobial genes mediating host recognition that exhibit signs of negative frequency-dependent selection when they are not in close linkage with nitrogen-fixation genes (Bailly et al. 2006), and genes involved in both signaling and nitrogen fixation show signs of elevated horizontal gene transfer (Bailly et al. 2006; Sun et al. 2006; Epstein et al. 2012; Parker 2012). Sequence conservation at rhizobial signaling genes may also be explained by one of our key results, in which hosts' ability to sanction allows hosts and symbionts to converge on compatible alleles at recognition and signaling loci (figs. 3, 6)such convergence should create selection to maintain compatibility.

\section{Conclusions}

Mutualistic interactions require communication between potential partners as well as cooperation once the interaction is underway. Previous theory of mutualism has not, however, explicitly included both of these systems of interaction. Our model of a symbiotic mutualism incorporating host recognition of symbiont signals alongside host sanctions against noncooperative symbionts proves to better reflect the apparent contradictions of empirical systems, maintaining mutualism and variation in interaction outcomes under conditions where neither system, on its own, can do so.

\section{Acknowledgments}

This work began as a project for the University of Minnesota Theory Under Construction discussion group. We also thank the Whitlock lab, attendees of the University of British Columbia Biodiversity Lunchtime Informal Seminar Series, S. L. Nuismer, and two anonymous reviewers. This work was funded by a National Science Foundation award to P.T. 
(grant 1237993; N. D. Young, principal investigator), and we developed and performed our simulations on computing systems maintained by the Minnesota Supercomputing Institute and Compute Canada's Westgrid network. J.B.Y. completed this work while a postdoctoral fellow with the CoAdapTree Project, supported by Genome Canada with cofunding from Genome British Columbia and Genome Quebec (S. N. Aitken, Project Leader; S. Yeaman and R. Hamelin, Co-Project Leaders).

\section{APPENDIX}

\section{Evolution of Linkage Disequilibrium}

Change in Linkage Disequilibrium in the PartnerRecognition Model

Under the QLE assumptions described in the main text and in the Mathematica notebooks deposited in the Dryad Digital Repository: http://dx.doi.org/10.5061/dryad.p2s02 (Yoder and Tiffin 2017), we can approximate change in linkage disequilibrium (LD) between the symbiont's mutualism and signaling loci, $\delta_{\mathrm{MS}}$ :

$$
\Delta \delta_{\mathrm{MS}} \approx-\frac{1}{2}\left[p_{\mathrm{M}}\left(1-p_{\mathrm{M}}\right) p_{\mathrm{S}}\left(1-p_{\mathrm{S}}\right)\left(2 p_{\mathrm{R}}-1\right) C_{\mathrm{S}}+\delta_{\mathrm{MS}}\right] .
$$

This term has the opposite sign of $\delta_{\mathrm{MS}}$, and LD between the symbiont cooperation and signaling loci will evolve toward zero, unless $-p_{\mathrm{M}}\left(1-p_{\mathrm{M}}\right) p_{\mathrm{S}}\left(1-p_{\mathrm{S}}\right)\left(2 p_{\mathrm{R}}-1\right) C_{\mathrm{S}}<\delta_{\mathrm{MS}}<0$ or $0<\delta_{\mathrm{MS}}<-p_{\mathrm{M}}\left(1-p_{\mathrm{M}}\right) p_{\mathrm{S}}\left(1-p_{\mathrm{S}}\right)\left(2 p_{\mathrm{R}}-1\right) C_{\mathrm{S}}$. For parameter values meeting the assumptions of the approximation (small $C_{\mathrm{S}}$ ), this means that LD between symbiont loci will remain negligible.

\section{Change in LD in the Model of Sanctions with Recognition}

The model of sanctions with recognition gives the following QLE approximations for change in LD between the host sanctions and recognition loci, $\delta_{\mathrm{HR}}$,

$$
\Delta \delta_{\mathrm{HR}} \approx \frac{1}{2}\left[p_{\mathrm{H}}\left(1-p_{\mathrm{H}}\right) p_{\mathrm{R}}\left(1-p_{\mathrm{R}}\right)\left(1-p_{\mathrm{M}}\right)\left(2 p_{\mathrm{S}}-1\right) \omega C_{\mathrm{H}}+\delta_{\mathrm{HR}}\right],
$$

and for change in LD between the symbiont cooperation and signaling loci, $\delta_{\mathrm{MS}}$,

$$
\Delta \delta_{\mathrm{MS}} \approx \frac{1}{2}\left[\left(1-p_{\mathrm{M}}\right) p_{\mathrm{M}}\left(1-p_{\mathrm{S}}\right) p_{\mathrm{S}}\left(2 p_{\mathrm{R}}-1\right)\left(\omega p_{\mathrm{H}} B_{\mathrm{S}}-C_{\mathrm{S}}\right)-\delta_{\mathrm{MS}}\right] .
$$

For the hosts, $\Delta \delta_{\mathrm{HR}}$ and $\delta_{\mathrm{HR}}$ have opposite signs, and LD between the sanctions and recognition loci evolves toward zero, unless $0<\delta_{\mathrm{HR}}<p_{\mathrm{H}}\left(1-p_{\mathrm{H}}\right) p_{\mathrm{R}}\left(1-p_{\mathrm{R}}\right)\left(1-p_{\mathrm{M}}\right)\left(2 p_{\mathrm{S}}-\right.$
1) $\omega C_{\mathrm{H}}$ or $p_{\mathrm{H}}\left(1-p_{\mathrm{H}}\right) p_{\mathrm{R}}\left(1-p_{\mathrm{R}}\right)\left(1-p_{\mathrm{M}}\right)\left(2 p_{\mathrm{S}}-1\right) \omega C_{\mathrm{H}}<$ $\delta_{\mathrm{HR}}<0$. In symbionts, LD between the cooperation and signaling loci evolves toward zero, unless $0<\delta_{\mathrm{MS}}<p_{\mathrm{M}}(1-$ $\left.p_{\mathrm{M}}\right) p_{\mathrm{S}}\left(1-p_{\mathrm{S}}\right)\left(2 p_{\mathrm{R}}-1\right)\left(\omega p_{\mathrm{H}} B_{\mathrm{S}}-C_{\mathrm{S}}\right)$ or $p_{\mathrm{M}}\left(1-p_{\mathrm{M}}\right) p_{\mathrm{S}}(1-$ $\left.p_{\mathrm{S}}\right)\left(2 p_{\mathrm{R}}-1\right)\left(\omega p_{\mathrm{H}} B_{\mathrm{S}}-C_{\mathrm{S}}\right)<\delta_{\mathrm{MS}}<0$. In both species, the conditions required for the approximation (small cost, $C_{i}$, and benefit, $B_{i}$, terms for each species) make the values of $\mathrm{LD}$ in these ranges negligibly small.

\section{Literature Cited}

Agrawal, A. F., and C. Lively. 2002. Infection genetics: gene-for-gene versus matching-alleles models and all points in between. Evolutionary Ecology Research 4:79-90.

Akçay, E., and E. L. Simms. 2011. Negotiation, sanctions, and context dependency in the legume-rhizobium mutualism. American Naturalist 178:1-14.

Althoff, D. M. 2016. Specialization in the yucca-yucca moth obligate pollination mutualism: a role for antagonism? American Journal of Botany 103:1803-1809.

Archetti, M., I. Scheuring, M. Hoffman, M. E. Frederickson, N. E. Pierce, and D. W. Yu. 2011a. Economic game theory for mutualism and cooperation. Ecology Letters 14:1300-1312.

Archetti, M., F. Úbeda, D. Fudenberg, J. Green, N. E. Pierce, and D. W. Yu. 2011b. Let the right one in: a microeconomic approach to partner choice in mutualisms. American Naturalist 177:75-85.

Axelrod, R., and W. Hamilton. 1981. The evolution of cooperation. Science 211:1390-1396.

Bailly, X., I. Olivieri, S. De Mita, J. C. Cleyet-Marel, and G. Béna. 2006. Recombination and selection shape the molecular diversity pattern of nitrogen-fixing Sinorhizobium sp. associated to Medicago. Molecular Ecology 15:2719-2734.

Barton, N. H., and M. Turelli. 1991. Natural and sexual selection on many loci. Genetics 127:229-255.

Batstone, R. T., E. M. Dutton, D. Wang, M. Yang, and M. E. Frederickson. 2017. The evolution of symbiont preference traits in the model legume Medicago truncatula. New Phytologist 213:18501861.

Béna, G., A. Lyet, T. Huguet, and I. Olivieri 2005. MedicagoSinorhizobium symbiotic specificity evolution and the geographic expansion of Medicago. Journal of Evolutionary Biology 18:15471558.

Bonhomme, M., S. Boitard, H. San Clemente, B. Dumas, N. D. Young, and C. Jacquet. 2015. Genomic signature of selective sweeps illuminates adaptation of Medicago truncatula to root-associated microorganisms. Molecular Biology and Evolution 32:2097-2110.

Bull, J. J., and W. R. Rice. 1991. Distinguishing mechanisms for the evolution of co-operation. Journal of Theoretical Biology 149:63-74.

Cullender, T. C., B. Chassaing, A. Janzon, K. Kumar, C. E. Muller, J. J. Werner, L. T. Angenent, et al. 2013. Innate and adaptive immunity interact to quench microbiome flagellar motility in the gut. Cell Host and Microbe 14:571-581.

Dieckmann, U., P. Marrow, and R. Law. 1995. Evolutionary cycling in predator-prey interactions: population dynamics and the red queen. Journal of Theoretical Biology 176:91-102.

Doebeli, M., and N. Knowlton. 1998. The evolution of interspecific mutualisms. Proceedings of the National Academy of Sciences of the USA 95:8676-8680. 
Dybdahl, M. F., C. E. Jenkins, and S. L. Nuismer. 2014. Identifying the molecular basis of host-parasite coevolution: merging models and mechanisms. American Naturalist 184:1-13.

Edwards, D. P., R. Arauco, M. Hassall, W. J. Sutherland, K. Chamberlain, L. J. Wadhams, and D. W. Yu. 2007. Protection in an ant-plant mutualism: an adaptation or a sensory trap? Animal Behaviour 74 : 377-385.

Edwards, D. P., M. Hassall, W. J. Sutherland, and D. W. Yu. $2006 a$. Assembling a mutualism: ant symbionts locate their host plants by detecting volatile chemicals. Insectes Sociaux 53:172-176.

. 2006b. Selection for protection in an ant-plant mutualism: host sanctions, host modularity, and the principal-agent game. Proceedings of the Roval Society B 273:595-602.

Epstein, B., A. Branca, J. Mudge, A. K. Bharti, R. Briskine, A. D. Farmer, M. Sugawara, N. D. Young, M. J. Sadowsky, and P. Tiffin. 2012. Population genomics of the facultatively mutualistic bacteria Sinorhizobium meliloti and S. medicae. PLoS Genetics 8(8):e1002868. doi:10.1371/journal.pgen.1002868.

Foster, K. R., and T. Wenseleers. 2006. A general model for the evolution of mutualisms. Journal of Evolutionary Biology 19:1283-1293.

Foster, K. R., T. Wenseleers, and F. L. W. Ratnieks. 2006. Kin selection is the key to altruism. Trends in Ecology and Evolution 21:57-60.

Frederickson, M. 2013. Rethinking mutualism stability: cheaters and the evolution of sanctions. Quarterly Review of Biology 88:269-295.

Ganapathy, G., and M. K. Uyenoyama. 2009. Site frequency spectra from genomic SNP surveys. Theoretical Population Biology 75: 346-354.

Grillo, M. A., J. R. Stinchcombe, and K. D. Heath. 2016. Nitrogen addition does not influence pre-infection partner choice in the legumerhizobium symbiosis. American Journal of Botany 103:1763-1770.

Heath, K. D., and J. R. Stinchcombe. 2014. Explaining mutualism variation: a new evolutionary paradox? Evolution 68:309-317.

Heath, K. D., and P. L. Tiffin. 2009. Stabilizing mechanisms in a legumerhizobium mutualism. Evolution 63:652-662.

Herre, E. A., and S. A. West. 1997. Conflict of interest in a mutualism: documenting the elusive fig wasp-seed trade-off. Proceedings of the Royal Society B 264:1501-1507.

Hoeksema, J. D. 2010. Ongoing coevolution in mycorrhizal interactions. New Phytologist 187:286-300.

Holland, J. N., and T. H. Fleming. 1999. Mutualistic interactions between Upiga virescens (Pyralidae), a pollinating seed-consumer, and Lophocereus schottii (Cactaceae). Ecology 80:2074-2084.

Jandér, K. C., and E. A. Herre. 2010. Host sanctions and pollinator cheating in the fig tree-fig wasp mutualism. Proceedings of the Roval Societv B 277:1481-1488.

. 2016. Host sanctions in Panamanian Ficus are likely based on selective resource allocation. American Journal of Botany 103:17531762.

Jones, E. I., M. E. Afkhami, E. Akçay, J. L. Bronstein, R. Bshary, M. E. Frederickson, K. D. Heath, et al. 2015. Cheaters must prosper: reconciling theoretical and empirical perspectives on cheating in mutualism. Ecology Letters 18:1270-1284.

Kiers, E. T., R. A. Rousseau, and R. F. Denison. 2006. Measured sanctions: legume hosts detect quantitative variation in rhizobium cooperation and punish accordingly. Evolutionary Ecology Research 8:1077-1086.

Kiers, E. T., R. A. Rousseau, S. A. West, and R. F. Denison. 2003. Host sanctions and the legume-rhizobium mutualism. Nature 425:78-81.

Kiester, A. R., R. Lande, and D. W. Schemske. 1984. Models of coevolution and speciation in plants and their pollinators. American Naturalist 124:220-243.
Kimbrel, J. A., W. J. Thomas, Y. Jiang, A. L. Creason, C. A. Thireault, J. L. Sachs, and J. H. Chang. 2013. Mutualistic co-evolution of type III effector genes in Sinorhizobium fredii and Bradyrhizobium japonicum. PLoS Pathogens 9(2):e1003204. doi:10.1371/journal.ppat.1003204.

Kirkpatrick, M., T. Johnson, and N. Barton. 2002. General models of multilocus evolution. Genetics 161:1727-1750.

Kopp, M., and S. Gavrilets. 2006. Multilocus genetics and the coevolution of quantitative traits. Evolution 60:1321-1336.

Laguerre, G., S. M. Nour, V. Macheret, J. Sanjuan, P. Drouin, and N. Amarger. 2001. Classification of rhizobia based on nodC and nifH gene analysis reveals a close phylogenetic relationship among Phaseolus vulgaris symbionts. Microbiology 147:981-993.

M'Gonigle, L. K., and S. P. Otto. 2011. Ploidy and the evolution of parasitism. Proceedings of the Roval Societv B 278:2814-2822.

Mutlu, E. A., A. Keshavarzian, J. Losurdo, G. Swanson, B. Siewe, C. Forsyth, A. French, et al. 2014. A compositional look at the human gastrointestinal microbiome and immune activation parameters in HIV infected subjects. PLoS Pathogens 10(2):e1003829. doi:10.1371 /journal.ppat.1003829.

Ness, J. H., W. F. Morris, and J. L. Bronstein. 2006. Integrating quality and quantity of mutualistic service to contrast ant species protecting Ferocactus wislizeni. Ecology 87:912-921.

Nuismer, S. L. 2017. Introduction to coevolutionary theory. W. H. Freeman, New York.

Nuismer, S. L., and M. F. Dybdahl. 2016. Quantifying the coevolutionary potential of multi-step immune defenses. Evolution 70:282-295.

Nuismer, S. L., R. Gomulkiewicz, and B. J. Ridenhour. 2010. When is correlation coevolution? American Naturalist 175:525-537.

Nuismer, S. L., and S. P. Otto. 2005. Host-parasite interactions and the evolution of gene expression. PLoS Biology 3(7):e203. doi:10.1371 /journal.pbio.0030203.

Nuismer, S. L., J. N. Thompson, and R. Gomulkiewicz. 1999. Gene flow and geographically structured coevolution. Proceedings of the Roval Societv B 266:605-609.

Ohtsuki, H. 2010. Evolutionary games in Wright's island model: kin selection meets evolutionary game theory. Evolution 64:3344-3353.

Okamoto, T., A. Kawakita, and M. Kato. 2007. Interspecific variation of floral scent composition in Glochidion and its association with host-specific pollinating seed parasite (Epicephala). Journal of Chemical Ecology 33:1065-1081.

Oldroyd, G. E., J. D. Murray, P. S. Poole, and J. A. Downie. 2011. The rules of engagement in the legume-rhizobial symbiosis. Annual Review of Genetics 45:119-144.

Paape, T., T. Bataillon, P. Zhou, T. J. Y. Kono, R. Briskine, N. D. Young, and P. Tiffin. 2013. Selection, genome-wide fitness effects and evolutionary rates in the model legume Medicago truncatula. Molecular Ecology 22:3525-3538.

Parker, M. A. 2012. Legumes select symbiosis island sequence variants in Bradyrhizobium. Molecular Ecology 21:1769-1778.

Pellmyr, O., and C. J. Huth. 1994. Evolutionary stability of mutualism between yuccas and yucca moths. Nature 372:257-260.

Pflughoeft, K. J., and J. Versalovic. 2012. Human microbiome in health and disease. Annual Review of Pathology 7:99-122.

Powell, A. F., and J. J. Doyle. 2016. Enhanced rhizobial symbiotic capacity in an allopolyploid species of Glycine (Leguminosae). American Lournal of Botany 103:1771-1782.

Regus, J. U., K. A. Gano, A. C. Hollowell, and J. L. Sachs. 2014. Efficiency of partner choice and sanctions in Lotus is not altered by nitrogen fertilization. Proceedings of the Roval Societv B 281:20132587. doi:10 $.1098 / \mathrm{rspb} .2013 .2587$. 
Sachs, J. L., U. G. Mueller, T. P. Wilcox, and J. J. Bull. 2004. The evolution of cooperation. Quarterly Review of Biology 79:135-160.

Sasaki, A. 2000. Host-parasite coevolution in a multilocus gene-forgene system. Proceedings of the Roval Societv B 267:2183-2188.

Schatz, B., C. Djieto-Lordon, L. Dormont, J. M. Bessière, D. McKey, and R. Blatrix. 2009. A simple non-specific chemical signal mediates defence behaviour in a specialised ant-plant mutualism. Current Biology 19(9):R361-R362.

Segraves, K. A. 2003. Understanding stability in mutualisms: can extrinsic factors balance the yucca-yucca moth interaction? Ecology 84:2943-2951.

Simms, E. L., and D. L. Taylor. 2002. Partner choice in nitrogen-fixation mutualisms of legumes and rhizobia. Integrative and Comparative Biology 42:369-380.

Soler, C., M. Hossaert-McKey, B. Buatois, J.-M. Bessière, B. Schatz, and M. Proffit. 2011. Geographic variation of floral scent in a highly specialized pollination mutualism. Phytochemistry 72:74-81.

Sullivan, J. T., and C. W. Ronson. 1998. Evolution of rhizobia by acquisition of a 500-kb symbiosis island that integrates into a phe-tRNA gene. Proceedings of the National Academv of Sciences of the USA 95:5145-5149.

Sun, S., H. Guo, and J. Xu. 2006. Multiple gene genealogical analyses reveal both common and distinct population genetic patterns among replicons in the nitrogen-fixing bacterium Sinorhizobium meliloti. Microbiology 152:3245-3259.

Svensson, G. P., M. O. Hickman Jr., S. Bartram, W. Boland, O. Pellmyr, and R. A. Raguso. 2005. Chemistry and geographic variation of floral scent in Yucca filamentosa (Agavaceae). American Journal of Botany 92:1624-1631.

Svensson, G. P., R. A. Raguso, R. Flatz, and C. I. Smith. 2016. Floral scent of Joshua trees (Yucca brevifoli sensu lato): divergence in scent profiles between species but breakdown of signal integrity in a narrow hybrid zone. American Journal of Botany 103:1793-1802.

Thompson, J. N. 2005. The geographic mosaic of coevolution. University of Chicago Press, Chicago.
. 2013. Relentless evolution. University of Chicago Press, Chicago.

Triplett, E. W., and M. J. Sadowsky. 1992. Genetics of competition for nodulation of legumes. Annual Review of Microbiology 46:399428.

Trivers, R. 1971. The evolution of reciprocal altruism. Quarterly Review of Biology 46:35-57.

West, S. A., E. T. Kiers, I. Pen, and R. F. Denison. 2002a. Sanctions and mutualism stability: when should less beneficial mutualists be tolerated? Journal of Evolutionary Biology 15:830-837.

West, S. A., E. T. Kiers, E. L. Simms, and R. F. Denison. 2002b. Sanctions and mutualism stability: why do rhizobia fix nitrogen? Proceedings of the Roval Society B 269:685-694.

Weyl, E. G., M. E. Frederickson, D. W. Yu, and N. E. Pierce. 2010. Economic contract theory tests models of mutualism. Proceedings of the National Academv of Sciences of the USA 107:15712-15716.

Yang, S., F. Tang, M. Gao, H. B. Krishnan, and H. Zhu. 2010. R genecontrolled host specificity in the legume-rhizobia symbiosis. Proceedings of the National Academy of Sciences of the USA 107:1873518740.

Yoder, J. B. 2016. Understanding the coevolutionary dynamics of mutualism with population genomics. American Journal of Botany 103:1742-1752.

Yoder, J. B., and S. L. Nuismer. 2010. When does coevolution promote diversification? American Naturalist 176:802-817.

Yoder, J. B., and P. L. Tiffin. 2017. Data from: Sanctions, partner recognition, and variation in mutualism. American Naturalist, Dryad Digital Repository, http://dx.doi.org/10.5061/dryad.p2s02.

Young, N. D., F. Debellé, G. E. D. Oldroyd, R. Geurts, S. B. Cannon, M. K. Udvardi, V. A. Benedito, et al. 2011. The Medicago genome provides insight into the evolution of rhizobial symbioses. Nature 480:520-524.

Associate Editor: Stephen B. Heard Editor: Judith L. Bronstein

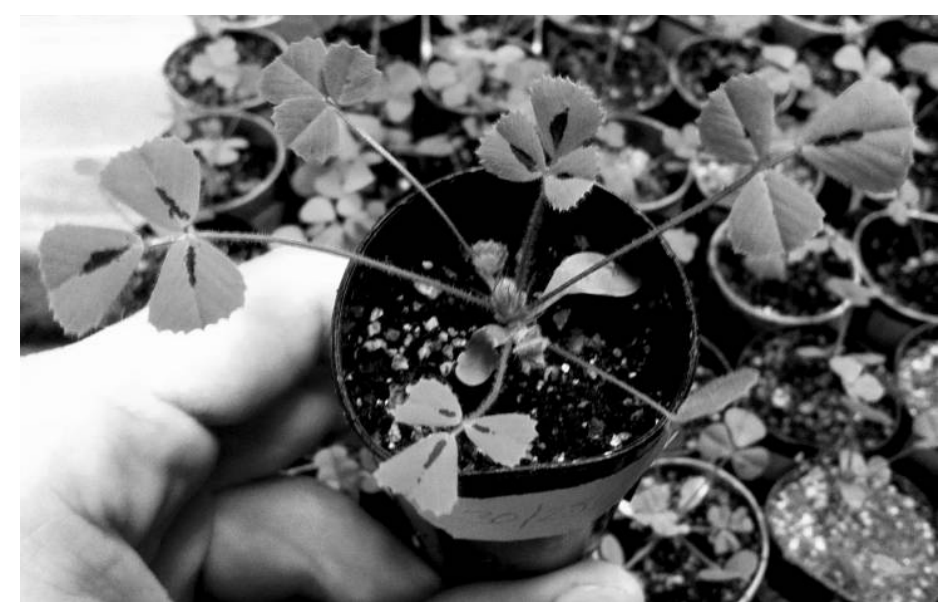

Medicago truncatula, or barrel clover, a member of the legume family that hosts bacteria in its roots. The bacteria transform nitrogen gas from the atmosphere into fertilizer for their host plant, and the host feeds the bacteria with sugar. Experiments with barrel clover and its mutualists have shown that signals between the plant and the bacteria are important in this interaction and provide an inspiration for the evolutionary models built by the authors. Photo credit: Jeremy Yoder. 